\title{
Regulation of acrosome reaction of fowl spermatozoa: evidence for the involvement of protein kinase $C$ and protein phosphatase-type 1 and/or -type $2 \mathrm{~A}$
}

\author{
K Ashizawa, G J Wishart ${ }^{1}$, S Katayama, D Takano, A R A H Ranasinghe, K Narumi and Y Tsuzuki \\ Laboratory of Animal Reproduction, Faculty of Agriculture, University of Miyazaki, Miyazaki 889-2192, Japan and \\ ${ }^{1}$ Division of Biotechnology, University of Abertay Dundee, Dundee, DD1 1HG, Scotland, UK \\ Correspondence should be addressed to K Ashizawa; Email: ashizawa@cc.miyazaki-u.ac.jp
}

\begin{abstract}
The signal transduction pathways involved in the regulation of the acrosome reaction and motility of fowl spermatozoa were investigated. The motility and acrosomal integrity of fowl spermatozoa in $\mathrm{TES} / \mathrm{NaCl}$ buffer, with or without homogenised inner perivitelline layers (IPVL), prepared from laid fowl eggs, was almost negligible at $40{ }^{\circ} \mathrm{C}$. In the presence of $2 \mathrm{mmol} \mathrm{CaCl} / \mathrm{l}$ at $40{ }^{\circ} \mathrm{C}$, motility became vigorous and the acrosome reaction was stimulated when IPVL was added. In the absence of $\mathrm{Ca}^{2+}$, motility was stimulated by the addition of calyculin A and okadaic acid, both specific inhibitors of protein phosphatase-type 1 (PP1) and -type 2A (PP2A), but Okadaic acid, which is a weaker inhibitor of PP1, did not completely restore motility at $40^{\circ} \mathrm{C}$. However, the acrosome reaction was significantly and equally stimulated in a dose-dependent manner by both inhibitors in the range of 10-1000 nmol/I, when spermatozoa were incubated with IPVL but without $\mathrm{Ca}^{2+}$. These inhibitors did not stimulate the acrosome reaction in the absence of IPVL. The vigorous motility of spermatozoa, stimulated by the addition of $\mathrm{Ca}^{2+}$, was reduced gradually as the concentrations of SC-9, a selective activator of protein kinase C (PKC), were increased and a similar SC-9-induced inhibition was observed in the acrosome reaction in the presence of $\mathrm{Ca}^{2+}$ and IPVL. These results confirm that IPVL is necessary for the activation of the acrosome reaction in fowl spermatozoa and that $\mathrm{Ca}^{2+}$ plays an important role in the stimulation of motility and acrosomal exocytosis. Furthermore, it appears that the intracellular molecular mechanisms for the regulation of acrosome reaction of fowl spermatozoa are different from those for the restoration of motility, i.e., protein dephosporylation involving PP1 and/or PP2A in the former, and PP1 alone in the latter case. In addition, the activation of PKC may contribute to a decrease in the flagellar movement and acrosome reaction of fowl spermatozoa.

Reproduction (2006) 131 1017-1024
\end{abstract}

\section{Introduction}

In birds, at fertilisation, access of the sperm plasma membrane to the oolemma is blocked by a glycoprotein layer, the inner perivitelline layer (IPVL), which surrounds the oocyte at ovulation (Bellairs et al. 1963, Kido \& Doi 1988). This layer may be considered to be analogous to the mammalian zona pellucida. In fact, it was shown that an IPVL glycoprotein of approximately $34 \mathrm{kDa}$ has a high degree of homology to mammalian zona pellucida protein-3 (Waclawek et al. 1998), which acts as the primary sperm-binding protein (Bleil \& Wassarman 1980), and triggers the acrosome reaction in mice (Bleil \& Wassarman 1983). Recently, it has been demonstrated that oligosaccharides isolated from fowlIPVL glycoproteins are capable of inducing the acrosome reaction in fowl spermatozoa. Preparations containing only $\mathrm{O}$-linked glycans were unable to induce the acrosome reaction whereas $\mathrm{N}$-linked oligosaccharides released from the IPVL by PNGaseF treatment could induce the acrosome reaction. Addition of galactose to terminal $\mathrm{N}$-acetyglucosamine residues suppressed the acrosome reaction-inducing capacity of the oligosaccharide preparation; however, this capacity could be restored by co-incubation with $\beta$-galactosidase. Therefore, it is suggested that the acrosome reaction-inducing factor is probably an $\mathrm{N}$-linked oligosaccharide with terminal $\mathrm{N}$-acetyl-glucosamine residues (Horrocks et al. 2000). Although some aspects of the inducer of the acrosome reaction in fowl spermatozoa have been identified, much remains to be learned about how the mechanism of the acrosome reaction is regulated within fowl spermatozoa. The addition of extracellular $\mathrm{Ca}^{2+}$ is found to be an absolute requirement for acrosomal 
exocytosis at the avian body temperature of $40{ }^{\circ} \mathrm{C}$ (Robertson 1999).

With regard to the control of sperm motility, unlike mammalian spermatozoa, fowl spermatozoa display the unique phenomenon of reversible temperature-dependent immobilisation: in simple salt solutions, they become immotile at $40^{\circ} \mathrm{C}$, but motility is restored by decreasing the temperature (Munro 1938, Ashizawa \& Nishiyama 1978, Ashizawa \& Wishart 1987, Wishart \& Ashizawa 1987, Ashizawa et al. 1989). It has been recognised that this flagellar movement of fowl spermatozoa may be regulated by a protein phosphorylationdephosphorylation system (Ashizawa et al. 2000). Protein phosphorylation by protein kinase $\mathrm{C}$ (PKC) seems to be involved in reducing the motility of fowl spermatozoa (Ashizawa et al. 1994a).

Furthermore, it has been proposed that dephosphorylation by the activation of protein phosphatase-type 1 (PP1), present in the fowl sperm axoneme and/or accessory cytoskeletal components may be involved in the inhibition of fowl sperm motility at $40{ }^{\circ} \mathrm{C}$, since, in addition to calyculin $\mathrm{A}$ and okadaic acid, inhibitors 1 and 2, specific inhibitors of PP1 (Cohen 1989), also stimulated the motility of demembranated spermatozoa at $40{ }^{\circ} \mathrm{C}$ (Ashizawa et al. 1994b). The regulatory serine/threonine protein phosphatases are classified into four main enzymes: type 1 (PP1), type 2A (PP2A), type 2B (PP2B), and type 2C (PP2C) (Cohen 1989). PP2B appears to be involved in the regulation of the acrosome reaction of fowl spermatozoa, but not their flagellar movement at body temperature, since the addition of specific inhibitors of PP2B significantly stimulated the acrosome reaction, but did not activate motility at $40{ }^{\circ} \mathrm{C}$ (Ashizawa et al. 2004). However, limited information is available on the involvement of PKC, PP1 or PP2A in the regulation of the acrosome reaction of fowl spermatozoa. Thus, in the following experiments, attempts were made to investigate the effects of PKC activator or PP1 and PP2A inhibitors on the acrosome reaction and motility of fowl spermatozoa.

\section{Materials and Methods}

\section{Animals and preparation of spermatozoa}

Commercial White Leghorn roosters (Babcock strain, Akagi Poultry Breeding Farm, Miyazaki, Japan) were used throughout the study. All birds were housed in individual cages and fed ad libitum on a commercial breeder diet. They were exposed to a photoperiod of $14 \mathrm{~h}$ light:10 h darkness.

Semen was collected by the method of Bogdonoff \& Shaffner (1954). Samples of semen pooled from four to six males were diluted approximately tenfold in $150 \mathrm{mmol} \mathrm{NaCl} / \mathrm{l}$ with $20 \mathrm{mmol}$ TES (N-Tris-[hydroxymethyl]-methyl-2-aminoethanesulfonic acid)/l at pH 7.4 and centrifuged at $700 \mathrm{~g}$ for $13 \mathrm{~min}$ at room temperature
(20-25 ${ }^{\circ} \mathrm{C}$ ). The washed spermatozoa were reconstituted in the same buffer to give a final concentration of approximately $6 \times 10^{8}$ cells $/ \mathrm{ml}$.

\section{Chemicals}

Calyculin A and okadaic acid, specific inhibitors of PP1 and PP2A, were purchased from Wako Pure Chemical Industries, Ltd. (Osaka, Japan). 1-(5-isoquinolinesulfonyl)-2-methylpiperazine dihydrochloride ( $\mathrm{H}-7)$, a broadbased inhibitor of serine/threonine protein kinase, and $\mathrm{N}$-(6-phenylhexyl)-5-chloro-1-naphthalenesulfonamide (SC-9), a selective activator of PKC, were obtained from Seikagaku Co., Ltd. (Tokyo, Japan). All were dissolved in DMSO as a stock solution and stored at $-30{ }^{\circ} \mathrm{C}$ until use. Adenosine $5^{\prime}$-triphosphate (ATP), bovine serum albumin, desiccated firefly tails, fluorescence isothiocyanate (FITC), conjugated peanut agglutinin (PNA), and TES were obtained from Sigma. Tween 20 was purchased from MP Biomedicals, Inc. (Aurora, OH, USA). Bicinchoninic acid (BCA) protein assay regent was obtained from Pierce Chemical Co. (Rockford, IL, USA). Sodium dodecyl sulfate-polyacrylamide gel electrophoresis (SDS-PAGE) molecular weight standards were purchased from Amersham Biosciences UK, Ltd. (Buckinghamshire, UK). Other chemicals were of reagent grade from Nacalai Tesque, Inc. (Kyoto, Japan).

\section{Antibodies}

A rabbit polyclonal antibody raised against amino acids 1-309 representing the full-length PP2A catalytic subunit of human origin was purchased from Santa Cruz Biotechnology, Inc. (Santa Cruz, CA, USA). Horseradish peroxidase conjugated donkey anti-rabbit immunoglobulin was obtained from Amersham Biosciences UK, Ltd. (Buckinghamshire, UK).

\section{Analysis of acrosome reaction and motility of spermatozoa}

Inner perivitelline layers (IPVL) were separated from laid fowl eggs (Robertson et al. 1997) and were homogenised using a Teflon glass homogeniser on ice. The protein concentrations of IPVL homogenates were adjusted to $75 \mu \mathrm{g} / \mathrm{ml}$ with TES/NaCl buffer ( $\mathrm{pH} 7.4$ ), using bovine serum albumin as a standard. Fowl spermatozoa at concentrations adjusted to $1.2 \times 10^{7}$ cells $/ \mathrm{ml}$ were incubated, with or without IPVL, for $30 \mathrm{~min}$ at $40^{\circ} \mathrm{C}$. The dose-response of the acrosome reaction was measured in the presence of various concentrations of calyculin A, okadaic acid, H-7 or SC-9 and the effects of the addition of $\mathrm{CaCl}_{2}$ were also examined. The inhibition constant $\left(K_{i}\right)$ values of calyculin A for PP1 and PP2A are around $2 \mathrm{nmol} / \mathrm{l}$ and $0.5-1 \mathrm{nmol} / \mathrm{l}$, respectively (Ishihara et al. 1989) and the $K_{i}$ values of okadaic acid 
for PP1 and PP2A are around $60-500 \mathrm{nmol} / \mathrm{l}$ and $0.5-1 \mathrm{nmol} / \mathrm{l}$, respectively (Ishihara et al. 1989). The $K_{i}$ values of $\mathrm{H}-7$ for PKC, cAMP-dependent protein kinase (PKA), protein kinase G (PKG) and myosin light chain kinase (MLCK) are $6.0 \mu \mathrm{mol} / \mathrm{l}, 3.0 \mu \mathrm{mol} / \mathrm{l}, 5.8 \mu \mathrm{mol} / \mathrm{l}$ and $97 \mu \mathrm{mol} / \mathrm{l}$, respectively (Kawamoto \& Hidaka 1984). The $K_{m}$ value of PKC, activated by SC-9 for substrate myosin light chain is $5.8 \mu \mathrm{mol} / \mathrm{l}$ (Ito et al. 1986). Ordinarily, 10to 100 -fold higher concentrations are required for the whole cells.

Acrosome-reacted spermatozoa were identified using FITC-conjugated PNA, which binds to acrosomereacted, but not acrosome-intact spermatozoa, using a fluorescence microscope at $\times 1000$, as described by Horrocks et al. (2000).

For motility determination, the suspension of spermatozoa was placed into a microscope slide chamber (Sekisui Chemical Co., Ltd., UR-157 type, Tokyo, Japan) on a thermostatically controlled warm plate, and the motility of spermatozoa was recorded by video microscopy (magnification on the 12-inch black and white monitor was approximately $\times 600)$ at $40{ }^{\circ} \mathrm{C}$ (Katz \& Overstreet 1981).

The percentages of acrosome-reacted and motile spermatozoa were derived by assessing a total of approximately 100 spermatozoa, distributed uniformly among three or more fields.

\section{Analysis of ATP concentrations of intact spermatozoa}

ATP content of spermatozoa in the absence of IPVL was assayed in boiled sperm extracts by firefly bioluminescence (Wishart 1982). Numbers of spermatozoa were estimated by the method of Wishart \& Ross (1985), using a double-beam spectrophotometer (Shimadzu, Model UV-150-02, Kyoto, Japan). The concentration of ATP was expressed in terms of nmol ATP $/ 10^{9}$ spermatozoa.

\section{Western immunoblot analysis}

Spermatozoa that had been washed as described above and adjusted to the concentrations of $4 \times 10^{8}$ cells $/ \mathrm{ml}$ were mixed with equal volumes of concentrated $(\times 2)$ Laemmli (1970) sample buffer and were boiled for $5 \mathrm{~min}$. Samples containing approximately $15 \mu \mathrm{g}$ protein were loaded onto $12.5 \%$ SDS-polyacrylamide slab gel and subjected to electrophoresis. For positive control, human breast carcinoma (T-47D) whole cell lysate (approximately $25 \mu \mathrm{g}$ protein) was loaded onto the same gel. Western blotting was performed according to the protocol of Towbin et al. (1979), with some modifications. Briefly, proteins were transferred electrophoretically to a polyvinylidene difluoride membrane sheet (Bio-Rad Laboratories, Inc., Hercules, CA, USA). After transfer, non-specific sites on the membranes were blocked by incubating them for $1.5 \mathrm{~h}$ at room temperature $\left(20-25^{\circ} \mathrm{C}\right)$ in $0.1 \%$ Tween 20 in Tris buffered saline (TTBS) containing $5 \%$ skimmed milk powder. The blots were then incubated overnight at $4{ }^{\circ} \mathrm{C}$ with the antibody to PP2A (1:200 dilution with TTBS). For negative control, the blots were incubated in TTBS alone. The blots were further incubated for $1 \mathrm{~h}$ at room temperature (20$25{ }^{\circ} \mathrm{C}$ ) with donkey anti-rabbit immunoglobulin conjugated with horseradish peroxidase (1:2000 dilution with TTBS). After each incubation, the membranes were rinsed extensively in TTBS. Finally, blots were developed with the Amersham ECL detection kit (Amersham Biosciences UK) for 5 min. Immunocomplexes were detected with Amersham photoimager system (Tyhoon 9410) exposures for around $5 \mathrm{~min}$.

\section{Statistical analysis}

Percentages of acrosome reaction and motility were transformed using arc sine transformation. All data were subjected to statistical analysis by Duncan's multiplerange tests (Duncan 1955).

\section{Results}

\section{Effects of calyculin A, okadaic acid, $\mathrm{H}-7$ and SC-9 on the motility and acrosome reaction of fowl spermatozoa}

The motility of spermatozoa in $\mathrm{TES} / \mathrm{NaCl}$ buffer alone (control) with or without IPVL at $40{ }^{\circ} \mathrm{C}$ was almost negligible (Figs. 1a-3a). When calyculin A was added, motility became vigorous (Fig. 1a), and the acrosome reaction was stimulated in the presence, but not in the absence of IPVL (Fig. 1b), in a dose-dependent manner, respectively. Similar dose-dependent stimulation of acrosome reaction was observed when okadaic acid was added to spermatozoa in the presence of IPVL (Fig. 2b). Okadaic acid also stimulated the motility of spermatozoa, although calyculin A appeared to be more potent, stimulating motility at a tenfold lower concentration than okadaic acid (Figs. 1a, 2a). The addition of $2 \mathrm{mmol} \mathrm{CaCl}_{2} / \mathrm{l}$ alone also stimulated motility, whether or not IPVL was present (Fig. 3a), and the acrosome reaction in the presence, but not in the absence of IPVL (Fig. 3b). The presence of both $\mathrm{Ca}^{2+}$ and inhibitor with IPVL resulted in a slightly higher stimulation of the acrosome reaction than the addition of $\mathrm{Ca}^{2+}$ or inhibitor alone, but this was not significant (Fig. 3b).

In the absence of added $\mathrm{Ca}^{2+}$, neither $\mathrm{H}-7$, a broadbased inhibitor of serine/threonine protein kinase, nor SC-9, a selective activator of PKC, restored motility at $40{ }^{\circ} \mathrm{C}$ or stimulated the acrosome reaction in the presence of IPVL (data not shown). Contrary to the absence of $\mathrm{Ca}^{2+}$, when $2 \mathrm{mmol} \mathrm{CaCl}_{2} / \mathrm{l}$ was added, no inhibition or stimulation was observed by the addition of $\mathrm{H}-7$ compared with the control (no addition of $\mathrm{H}-7$ ): the presence of $\mathrm{H}-7$ permitted the restoration of motility at 

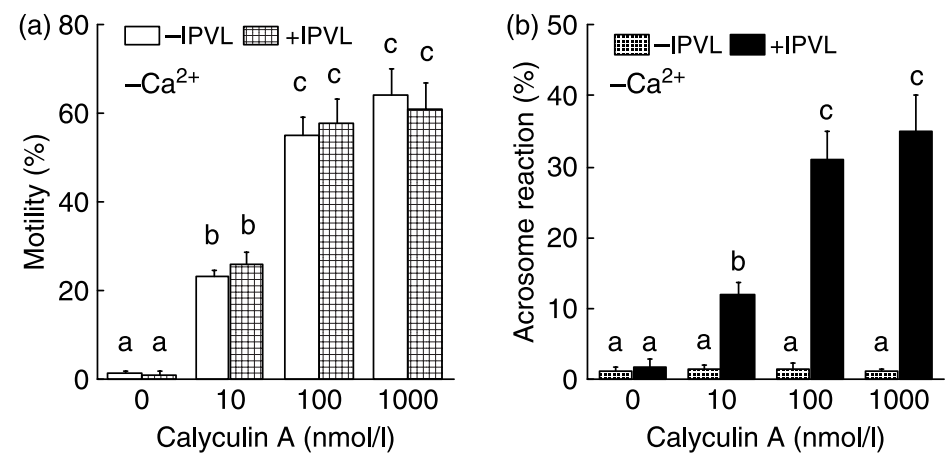

Figure 1 Effect of calyculin A on (a) the motility and (b) acrosome reaction of fowl spermatozoa incubated with or without IPVL in the absence of $\mathrm{Ca}^{2+}$ at $40{ }^{\circ} \mathrm{C}$. Each value represents the mean ( \pm S.E.M.) of five samples of spermatozoa. Values with different superscripts differ significantly $(P<0.05)$ from each other.

$40^{\circ} \mathrm{C}$ (Fig. 4a) and, in the prescence of IPVL, induced the acrosome reaction (Fig. 4b) in the range of 1-100 micromol/l. However, the vigorous motility of spermatozoa, stimulated by the addition of $\mathrm{Ca}^{2+}$ was reduced gradually as the concentrations of SC-9 were increased (Fig. 5a) and a similar SC-9-induced inhibition was observed in the acrosome reaction in the presence of $\mathrm{Ca}^{2+}$ and IPVL (Fig. 5b).

\section{Effects of calyculin A, okadaic acid, $\mathrm{H-7}$ and SC-9 on the ATP concentrations of fowl spermatozoa}

The ATP concentrations of spermatozoa following exposure to $100 \mathrm{nmol}$ okadaic acid/l, $100 \mu \mathrm{mol} \mathrm{H}-7 / \mathrm{l}$ or $10 \mu \mathrm{mol}$ SC- $9 / \mathrm{l}$ alone at $40{ }^{\circ} \mathrm{C}$ had almost the same values compared to those of untreated spermatozoa (control) (around $40-45 \mathrm{nmol}$ per $10^{9}$ spermatozoa). Additionally, the ATP concentrations of spermatozoa decreased significantly in the presence of $2 \mathrm{mmol}$ $\mathrm{CaCl}_{2} / \mathrm{I}$ or $100 \mathrm{nmol}$ calyculin $\mathrm{A} / \mathrm{l}$ alone, presumably due to the restoration of motility (around $30 \mathrm{nmol}$ per $10^{9}$ spermatozoa). Thus, the addition of inhibitors or activator is not simply affecting membrane damage or inhibiting energy production in these spermatozoa, but may be acting on some part of the regulatory cascade of motility or the acrosome reaction.

\section{Immunoblot identification of PP2A in fowl spermatozoa}

No appreciable immunoreactive protein was detected in the negative control lane (no antibody). In contrast, a protein of approximately $36 \mathrm{kDa}$ was recognised by the anti-PP2A antibody, which corresponds to the molecular weight of the catalytic subunit of PP2A, even though the visible immunoreactive band was faint, compared with the positive control (Fig. 6).

\section{Discussion}

The acrosome reaction, which is an exocytotic secretory response, is required for sperm penetration and fusion with the egg investments and plasma membrane (Rotem et al. 1992), and is regulated by the activation of compartmentalised intracellular signalling pathways (Urner \& Sakkas 2003). The molecular mechanisms and the signal transduction pathways mediating the processes of acrosome reaction are partially defined: changes in protein phosphorylation and
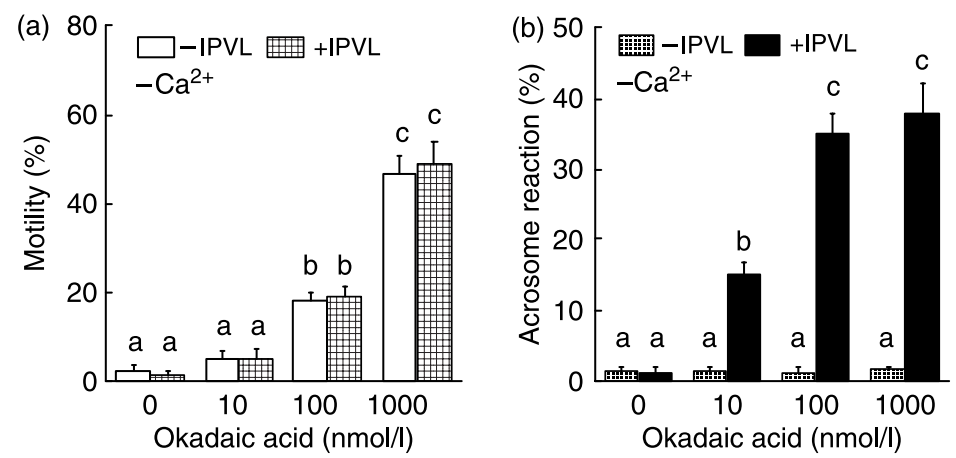

Figure 2 Effect of okadaic acid on (a) the motility and (b) acrosome reaction of fowl spermatozoa incubated with or without IPVL in the absence of $\mathrm{Ca}^{2+}$ at $40{ }^{\circ} \mathrm{C}$. Each value represents the mean ( \pm s.E.M.) of five samples of spermatozoa. Values with different superscripts differ significantly $(P<0.05)$ from each other. 

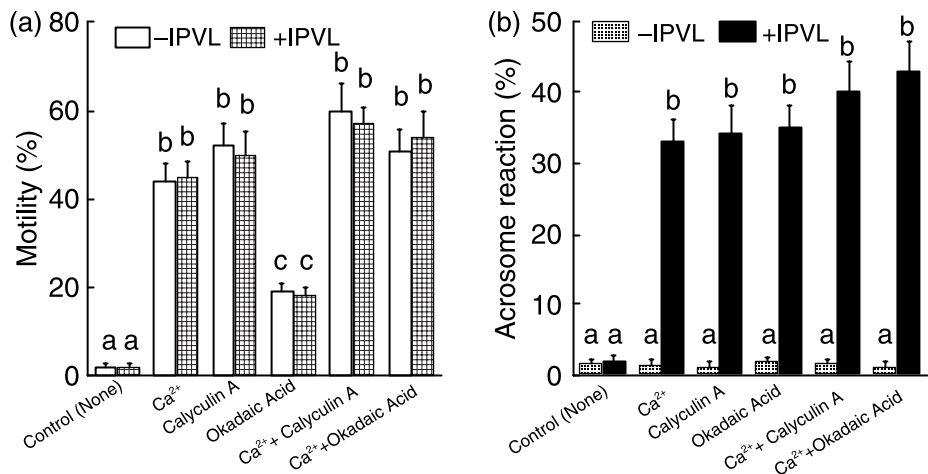

Figure $3 \mathrm{Effect}$ of $\mathrm{Ca}^{2+}(2 \mathrm{mmol} / \mathrm{l})$, calyculin $\mathrm{A}(100 \mathrm{nmol} / \mathrm{l})$ and okadaic acid $(100 \mathrm{nmol} / \mathrm{l})$ on (a) the motility and (b) acrosome reaction of fowl spermatozoa incubated with or without IPVL at $40^{\circ} \mathrm{C}$. Each value represents the mean ( \pm s.E.M.) of five samples of spermatozoa. Values with different superscripts differ significantly $(P<0.05)$ from each other.

dephosphorylation of sperm proteins, including $\mathrm{Ca}^{2+}$ dependent processes, seem to play a primary role in the second messenger regulatory mechanisms (for a review, see Benoff 1998, Breitbart \& Naor 1999, Baldi et al. 2000, Guraya 2000, Topfer-Petersen et al. 2000, Urner \& Sakkas 2003). There is evidence for the involvement of cAMP-dependent protein kinase (PKA) in the mammalian acrosome reaction: adenylate cyclase activity and cAMP generation increased during this process in human spermatozoa (De Jonge et al. 1991); adenylate cyclase stimulators such as forskolin, and the cAMP analogue dibutyryl cAMP, induced the acrosome reaction in a dose-dependent manner in human and ram spermatozoa (Anderson et al. 1992, Garde \& Roldan 2000, Harrison \& Meizel 2000); and PKA inhibitors have been reported to suppress human sperm acrosome reaction (Harrison \& Meizel 2000).

PKC activators, such as phorbol esters and synthetic diacylglycerol (DAG) induce the mammalian sperm acrosome reaction, and the localisation of PKC in the acrosomal region of the sperm head also indicates the involvement of PKC in this process (Breitbart \& Naor 1999). In addition, induction of the human sperm acrosome reaction by solubilised zona pellucida was partially reduced by pre-treatment with inhibitors of PKA, PKC and protein kinase G (PKG) and their combined inhibitory effect was additive (Bielfeld et al. 1994). These results suggest a concomitant role for PKA, PKC and PKG in human ZP-induced acrosome reaction (Bielfeld et al. 1994). Protein tyrosine kinase also appears to be involved in the regulation of the acrosome reaction of mammalian spermatozoa (for a review, see Urner \& Sakkas 2003).

From our previous work, PKC appeared to be present in fowl spermatozoa, since immunoblot analysis of fowl sperm proteins showed that a protein of approximately $80 \mathrm{kDa}$ was recognised by an antibody to PKC (Ashizawa et al. 1994a). Furthermore, the present study demonstrates that the activation of PKC may contribute to a decrease in the acrosome reaction of fowl spermatozoa, since the addition of SC-9, a selective activator of PKC, inhibited the acrosome reaction response to IPVL and $\mathrm{Ca}^{2+}$ in a dose-dependent manner. A similar inhibition by SC-9 of motility stimulation by $\mathrm{Ca}^{2+}$ was consistent with previous work (Ashizawa et al. 1994a). From these results, it seems that PKC has an opposite effect on the
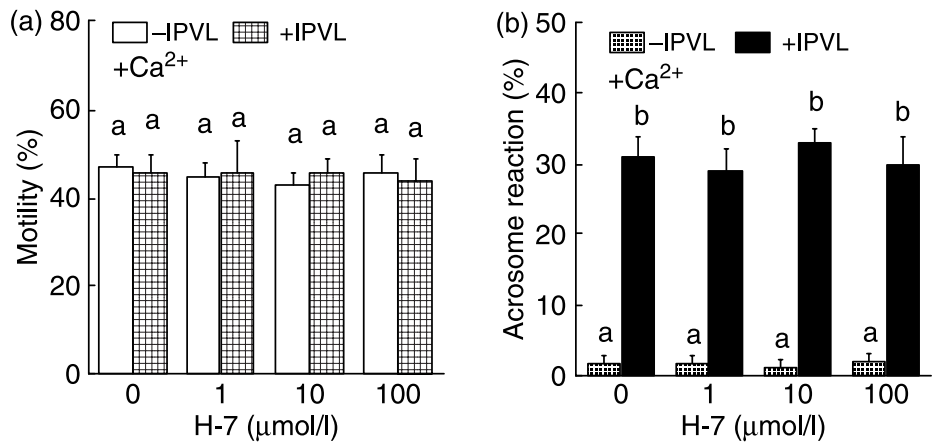

Figure 4 Effect of $\mathrm{H}-7$ on (a) the motility and (b) acrosome reaction of fowl spermatozoa incubated with or without IPVL in the presence of 2 mmol $\mathrm{CaCl}_{2} / \mathrm{l}$ at $40{ }^{\circ} \mathrm{C}$. $\mathrm{H}-7$ was added at the start of incubation and spermatozoa were incubated for a total of $30 \mathrm{~min}$. After 15 min of incubation, CaCl was added to the inhibitor-treated spermatozoa. Each value represents the mean ( \pm s.E.M.) of five samples of spermatozoa. Values with different superscripts differ significantly $(P<0.05)$ from each other. 

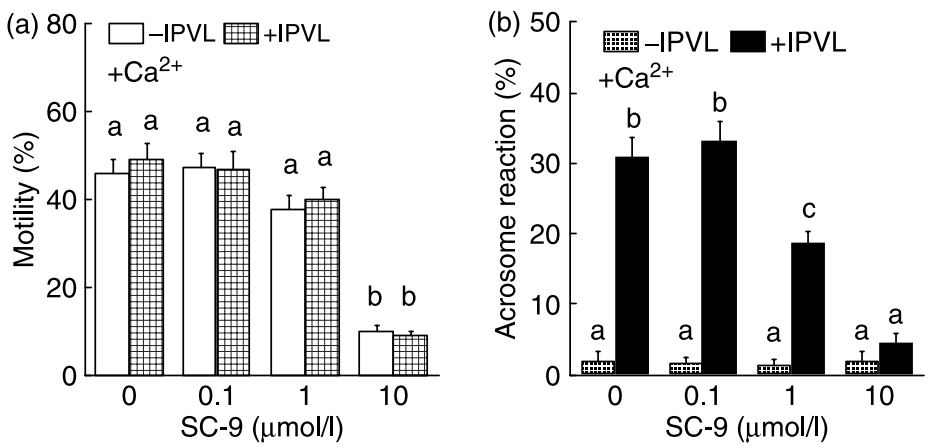

Figure 5 Effect of SC-9 on (a) the motility and (b) acrosome reaction of fowl spermatozoa incubated with or without IPVL in the presence of 2 mmol $\mathrm{CaCl}_{2} / \mathrm{l}$ at $40{ }^{\circ} \mathrm{C}$. SC-9 was added at the start of incubation and spermatozoa were incubated for a total of $30 \mathrm{~min}$. After 15 min of incubation, CaCl 2 was added to the activator-treated spermatozoa. Each value represents the mean ( \pm s.E.M.) of five samples of spermatozoa. Values with different superscripts differ significantly $(P<0.05)$ from each other.

regulation of fowl sperm motility and acrosome reaction than that of mammalian spermatozoa. However, such a difference is not surprising, given that several lines of evidence point towards differential regulation of sperm motility in fowl and mammals. First, demembranated fowl spermatozoa can be motile even in the presence of millimolar concentrations of $\mathrm{Ca}^{2+}$ (Ashizawa et al. 1989), whereas such high concentrations of $\mathrm{Ca}^{2+}$ inhibit the motility of demembranated mammalian spermatozoa (White \& Voglmayer 1986, Feng et al. 1988). Secondly, cAMP is indispensable for the initiation and stimulation of flagellar motility of mammalian spermatozoa (for a review, see Tash \& Means 1983, Lindemann \& Kanous 1989), but is not necessary for fowl spermatozoa, especially at $40{ }^{\circ} \mathrm{C}$ (Ashizawa et al. 1992).

In the study reported here, the addition of $\mathrm{H}-7$, a broad-based inhibitor of serine/threonine protein kinase (especially of PKC, PKA and PKG), did not appreciably affect the motility or acrosome reaction of fowl spermatozoa. These results suggest that fowl sperm motility and the acrosome reaction may not be simply stimulated or inhibited by changes in the activity of these kinases, especially PKC. Perhaps their inhibition involves a PKC-dependent phosphoprotein(s) that is active only when phosphorylated more than a certain threshold amount (e.g. in response to SC-9). In contrast, when this protein(s) is dephosphorylated or phosphorylated less than a threshold amount (e.g. by the addition of $\mathrm{H}-7$ or under control conditions) spermatozoa maintain, but do not increase their motility or acrosome reaction status. However, in this study, the target and precise mechanisms of action of PKC remain to be elucidated. Further study is needed to examine which protein(s) is altered during the inhibition of fowl sperm motility or acrosome reaction by the activation of PKC.

If phosphorylation by protein kinases is involved in the acrosome reaction, then dephosphorylation of proteins by specific regulatory phosphatases should also affect the acrosome reaction. Such regulatory serine/threonine protein phosphatases are classified into four main enzymes; type 1 (PP1), type 2A (PP2A), type 2B (PP2B) and type 2C (PP2C) (Cohen 1989). Another phosphatase family is protein tyrosine phosphatase (PTPs), which removes phosphate groups from phosphorylated tyrosine residues of proteins (for a review, see Montalibet et al. 2005). Both mouse and human spermatozoa contain highly active tyrosine phosphatases and inhibition of tyrosine phosphatases with sodium pervanadate, bis $(\mathrm{N}, \mathrm{N}$-dimethylhydroxoamido) hydroxovanadate, ethyl-3,4-dephostatin and phenylarsine oxide prevents the acrosome reaction, suggesting that PTPs play a role in mammalian sperm exocytosis (Tomes et al. 2004). With regard to fowl spermatozoa, it is suggested that PP2B appears to be involved in the regulation of the acrosome reaction, since the addition of specific inhibitors of PP2B, such as

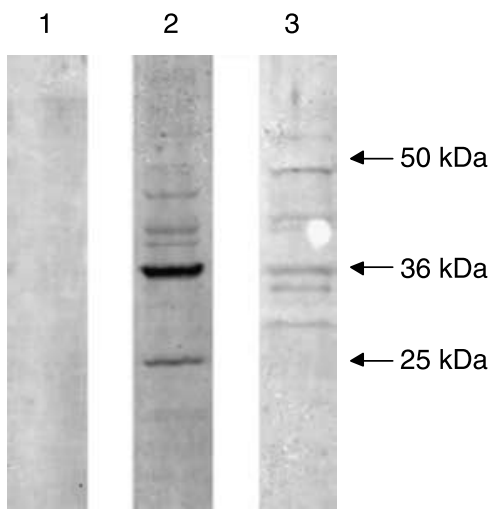

Figure 6 Immunoblot analysis of fowl sperm protein phosphatase type2A. Lane 1: fowl sperm lysate incubated without a PP2A polyclonal antibody (negative control); lane 2: human breast carcinoma (T-47D) whole cell lysate incubated with a PP2A polyclonal antibody (positive control); lane 3: fowl sperm lysate incubated with a rabbit polyclonal antibody raised against amino acids 1-309, representing full-length PP2A catalytic subunit of human origin. 
deltamethrin or fenvalerate, significantly stimulated the acrosome reaction (Ashizawa et al. 2004).

Okadaic acid is a very potent inhibitor of PP1 and PP2A (Cohen et al. 1990). Calyculin A has a potency similar to that of okadaic acid as an inhibitor of PP2A, but is 10- to 100-fold more effective as an inhibitor of PP1 (Ishihara et al. 1989). The present study showed that the motility of fowl spermatozoa at $40{ }^{\circ} \mathrm{C}$ was stimulated by calyculin $\mathrm{A}$ and was effective at 10- to 100-fold lower concentrations of calyculin A than those of okadaic acid, confirming earlier results (Ashizawa et al. 1994b). In contrast, the acrosome reaction in the presence of IPVL was stimulated in the same dose-dependent manner by both 10-1000 nmol/l okadaic acid and calyculin A. These results suggest that PP1 and/or PP2A are involved in the regulation of acrosome reaction but that only PP1 is involved in the regulation of motility of fowl spermatozoa. It seems that both phosphatases are present in fowl spermatozoa, since immunoblotting of sperm extract using an antibody to PP1 $\alpha$ revealed a major cross-reacting protein of $36-37 \mathrm{kDa}$ which corresponds to the molecular weight of the catalytic subunit of PP1 $\alpha$ (Ashizawa et al. 1994b), and in this study, a protein of approximately $36 \mathrm{kDa}$ was recognised by anti-PP2A antibody which corresponds to the molecular weight of the catalytic subunit of PP2A.

Therefore, in conclusion, different or different combinations of protein phosphatases are involved in the regulation of the acrosome reaction of fowl spermatozoa than those involved in the regulation of fowl sperm motility, i.e., protein dephosphorylation by PP2B and PP1 and/or PP2A in the former, and PP1 alone in the latter case. In addition, the activation of PKC may contribute to a decrease in the flagellar movement and acrosome reaction of fowl spermatozoa.

\section{Acknowledgements}

This study was supported by a grant from the Ministry of Education, Science and Culture, Japan. The authors declare that there is no conflict of interest that would prejudice the impartiality of this scientific work.

\section{References}

Anderson RA Jr, Feathergill KA, De Jonge CJ, Mack SR \& Zaneveld LJD 1992 Facilitative effect of pulsed addition of dibutyryl cAMP on the acrosome reaction of noncapacitated spermatozoa. Journal of Andrology 13 398-408.

Ashizawa K \& Wishart GJ 1987 Resolution of the sperm motilitystimulating principle of fowl seminal plasma into $\mathrm{Ca}^{2+}$ and an unidentified low molecular weight factor. Journal of Reproduction and Fertility 81 495-499.

Ashizawa K \& Nishiyama H 1978 Effects of temperature on the vigour of motility, oxygen consumption and duration of motility of fowl spermatozoa under aerobic conditions. Japanese Poultry Science 15 264-266.
Ashizawa K, Maeda S \& Okauchi K 1989 The mechanisms of reversible immobilization of fowl spermatozoa at body temperature. Journal of Reproduction and Fertility 86 271-276.

Ashizawa K, Katayama S \& Tsuzuki Y 1992 Regulation of flagellar motility by temperature-dependent phosphorylation of a $43 \mathrm{kDa}$ axonemal protein in fowl spermatozoa. Biochemical and Biophysical Research Communications 185 740-745.

Ashizawa K, Katayama S, Kobayashi T \& Tsuzuki Y 1994a Possible role of protein kinase $\mathrm{C}$ in regulation of flagellar motility and intracellular free $\mathrm{Ca}^{2+}$ concentration of fowl spermatozoa. Journal of Reproduction and Fertility 101 511-517.

Ashizawa K, Wishart GJ, Tomonaga H, Nishinakama K \& Tsuzuki Y $1994 b$ Presence of protein phosphatase type 1 and its involvement in temperature-dependent flagellar movement of fowl spermatozoa. FEBS Letters 350 130-134.

Ashizawa K, Wishart GJ \& Tsuzuki Y 2000 Avian sperm motility: environmental and intracellular regulation. Avian and Poultry Biology Reviews 11 161-172.

Ashizawa K, Wishart GJ, Ranasinghe ARAH, Katayama S \& Tsuzuki Y 2004 Protein phosphatase-type $2 \mathrm{~B}$ is involved in the regulation of the acrosome reaction but not in the temperature-dependent flagellar movement of fowl spermatozoa. Reproduction 128 783-787.

Baldi E, Luconi M, Bonaccorsi L, Muratori M \& Forti G 2000 Intracellular events and signalling pathways involved in sperm acquisition of fertilizing capacity and acrosome reaction. Frontiers in Bioscience 5 e110-e123.

Bellairs R, Harkness M \& Harkeness RD 1963 The vitelline membrane of the hen's ovum: a chemical and electron microscopical study. Journal of Ultrastructure Research 8 339-359.

Benoff S 1998 Modelling human sperm-egg interactions in vitro: signal transduction pathways regulating the acrosome reaction. Molecular Human Reproduction 4 453-471.

Bielfeld P, Anderson RA, Mack SR, De Jonge CJ \& Zaneveld LJD 1994 Are capacitation or calcium ion influx required for the human sperm acrosome reaction? Fertility and Sterility 62 1255-1261.

Bleil JD \& Wassarman PM 1980 Mammalian sperm-egg interaction: identification of a glycoprotein in mouse egg zonae pellucidae possessing receptor activity for sperm. Cell 20 873-882.

Bleil JD \& Wassarman PM 1983 Sperm-egg interactions in the mouse: sequence of events and induction of the acrosome reaction by a zona pellucida glycoprotein. Developmental Biology 95 317-324.

Bogdonoff PD Jr \& Shaffner CS 1954 The effect of $\mathrm{pH}$ on in vitro survival, metabolic activity, and fertilizing capacity of chicken semen. Poultry Science 33 665-669.

Breitbart H \& Naor Z 1999 Protein kinases in mammalian sperm capacitation and the acrosome reaction. Reviews of Reproduction 4 151-159.

Cohen P 1989 The structure and regulation of protein phosphatases. Annual Review of Biochemistry $\mathbf{5 8} 453-508$.

Cohen P, Holmes CFB \& Tsukitani Y 1990 Okadaic acid: a new probe for the study of cellular regulation. Trends in Biochemical Sciences 15 98-102.

De Jonge C, Han H-L, Lawrie H, Mack SR \& Zaneveld LJD 1991 Modulation of the human sperm acrosome reaction by effector of adenylate cyclase/cyclic AMP second messanger pathway. Journal of Experimental Zoology 258 113-125.

Duncan DB 1955 Multiple range and multiple Ftests. Biometrics 11 1-42.

Feng B, Bhattacharyya A \& Yanagimachi R $1988 \mathrm{Ca}^{2+}$ is essential for the motility of plasma membrane-intact, but not of demembranated, hamster spermatozoa. Andrologia 20 155-162.

Garde J \& Roldan ER 2000 Stimulation of $\mathrm{Ca}^{2+}$-dependent exocytosis of the sperm acrosome by cAMP acting downstream of phospholipase $\mathrm{A}_{2}$. Journal of Reproduction and Fertility 118 57-68.

Guraya SS 2000 Cellular and molecular biology of capacitation and acrosome reaction in spermatozoa. International Review of Cytology 199 1-64.

Harrison DA \& Meizel S 2000 Involvement of protein kinase A and A kinase anchoring protein in the progesterone-initiated human sperm acrosome reaction. Biology of Reproduction 62 811-820. 
Horrocks AJ, Stewart S, Jackson L \& Wishart GJ 2000 Induction of acrosomal exocytosis in chicken spermatozoa by inner perivitellinederived N-linked glycans. Biochemical and Biophysical Research Communications 278 84-89.

Ishihara $H$, Martin BL, Brautigan DL, Karaki H, Ozaki H, Kato $Y$, Fusetani N, Watabe S, Hashimoto K, Uemura D \& Hartshorne DJ 1989 Calyculin A and okadaic acid: inhibitors of protein phosphatase activity. Biochemical and Biophysical Research Communications 159 871-877.

Ito M, Tanaka T, Inagaki M, Nakanishi K \& Hidaka H 1986 N-(6phenylhexyl)-5-chloro-1-naphthalenesulfonamide, a novel activator of protein kinase C. Biochemistry 25 4179-4184.

Katz DF \& Overstreet JW 1981 Sperm motility assessment by videomicrography. Fertility and Sterility 35 188-193.

Kawamoto S \& Hidaka H 1984 1-(5-Isoquinolinesulfonyl)-2-methylpiperazine $(\mathrm{H}-7)$ is a selective inhibitor of protein kinase $\mathrm{C}$ in rabbit platelets. Biochemical and Biophysical Research Communications 125 258-264.

Kido S \& Doi Y 1988 Separation and properties of the inner and outer layers of the vitelline membrane of hen's eggs. Poultry Science $\mathbf{6 7}$ 476-486.

Laemmli UK 1970 Cleavage of structural proteins during the assembly of the head of bacteriophage $\mathrm{T}_{4}$. Nature 227 680-685.

Lindemann CB \& Kanous KS 1989 Regulation of mammalian sperm motility. Archives of Andrology 23 1-22.

Montalibet J, Skorey KI \& Kennedy BP 2005 Protein tyrosine phosphatase: enzymatic assays. Methods 35 2-8.

Munro SS 1938 Fowl sperm immobilization by a temperature-media interaction and its biological significance. Quarterly Journal of Experimental Physiology 27 281-287.

Robertson L 1999 Sperm-egg interaction in birds: assays and mechanisms. PhD Thesis. University of Abertay Dundee.

Robertson L, Brown HL, Staines HJ \& Wishart GJ 1997 Characterization and application of an avian in vitro spermatozoa-egg interaction assay using the inner perivitelline layer from laid chicken eggs. Journal of Reproduction and Fertility 110 205-211.

Rotem R, Paz GF, Homonnai ZT, Kalina M, Lax J, Breitbart H \& Naor Z $1992 \mathrm{Ca}^{2+}$-independent induction of acrosome reaction by protein kinase C in human sperm. Endocrinology 131 2235-2243.
Tash JS \& Means AR 1983 Cyclic adenosine 3', 5' monophosphate, calcium and protein phosphorylation in flagellar motility. Biology of Reproduction 28 75-104.

Tomes CN, Roggero CM, De Blas G, Saling PM \& Mayorga LS 2004 Requirement of protein tyrosine kinase and phosphatase activities for human sperm exocytosis. Developmental Biology 265 399-415.

Topfer-Petersen E, Petrounkina AM \& Ekhlasi-Hundrieser M 2000 Oocyte-sperm interactions. Animal Reproduction Science 60-61 653-662.

Towbin H, Staehelin T \& Gordon J 1979 Electrophoretic transfer of proteins from polyacrylamide gels to nitrocellulose sheets: procedure and some applications. PNAS 76 4350-4354.

Urner F \& Sakkas D 2003 Protein phosphorylation in mammalian spermatozoa. Reproduction 125 17-26.

Waclawek M, Foisner R, Nimpf J \& Schneider WJ 1998 The chicken homologue of zona pellucida protein-3 is synthesized by granulosa cells. Biology of Reproduction 59 1230-1239.

White IG \& Voglmayr JK 1986 ATP-induced reactivation of ram testicular, cauda epididymal, and ejaculated spermatozoa extracted with Triton X-100. Biology of Reproduction 34 183-193.

Wishart GJ 1982 Maintenance of ATP concentrations in and of fertilizing ability of fowl and turkey spermatozoa in vitro. Journal of Reproduction and Fertility 66 457-462.

Wishart GJ \& Ashizawa K 1987 Regulation of the motility of fowl spermatozoa by calcium and cAMP. Journal of Reproduction and Fertility 80 607-611.

Wishart GJ \& Ross FH 1985 Characterization of a spectrophotometric technique for the estimation of fowl and turkey sperm motility. Gamete Research 11 169-178.

Received 13 December 2005

First decision 14 February 2006

Revised manuscript received 1 March 2006

Accepted 7 March 2006 